\title{
Наименования орудий лова в русском и польском рыболовных социолектах (мотивационный и словообразовательный аспекты)
}

\author{
Names of the Fishing Tackle in the Russian and Polish \\ Fishing Sociolects (Motivational and Word-Formation Aspects)
}

\author{
Александра Земба \\ (Катовице, Польша)
}

\section{Абстракт:}

Целью настоящей статьи является представление недооценённого обилия польской и русской рыболовной лексики. Из-за своеобразно развлекательного характера деятельности, этот научный материал не пользуется большим признанием среди лингвистов. В статье анализу подверглись наименования некоторых орудий лова, исследование которых позволяет узнать наиболее выразительные черты рыболовной лексики. Каждое наименование рассматривается с точки зрения мотивационного и словообразовательного аспектов, а к некоторым определениям приводится пример их употребления в речи рыболовов. Наблюдаются сходства в польской и русской рыболовной номенклатуре, как и различия, вытекающие из территориальной и культурной дифференциации. В большинстве случаев анализ обнаружил те же самую словообразовательную основу единиц и похожую путь формирования социолектов. Материалом послужили слова, зафиксированные в специализированных словарях и на веб-сайтах, посвященных рыбалке.

\section{Ключевые слова:}

рыбалка; мотивационный аспект; словообразовательный аспект; рыболовный социолект; сравнительный анализ 


\section{Abstract:}

The aim of the article is to present the underrated abundance of the Polish and Russian fishing vocabulary. Because of the entertaining nature of fishing, this scientific material does not enjoy much recognition among the linguists. The article analyzes the names defining some fishing tackle, the study of which allows to find out the most expressive features of the fishing vocabulary. Each name is considered from the point of view of the motivational and word-formation aspects. Some names contain the examples of their usage in the fishermen's speech. There are similarities in the Polish and Russian fishing nomenclature, as well as the differences arising from the territorial and the cultural differentiation. In most cases, the analysis revealed the same word-formative basis of the units as well as the similar process of forming the sociolects. The material is based on words recorded in specialized dictionaries and on fishing websites.

\section{Key words:}

fishing; motivational aspect; word-formation aspect; fishing sociolect; comparative analysis

Жизнь и поведение человека с момента его выделения в качестве самостоятельного вида млекопитающих всегда были неразрывно связаны с природной средой и всеми её элементами. Не подлежит сомнению тот факт, что вода уже с древнейших времён делает возможным существование любого организма. В истории человечества, в зависимости от характера окружающей среды, наряду с собирательством, охотой, сельским хозяйством и скотоводством, рыболовство было одинаково важным. Это проявление культурной активности является одной из самых архаичных профессий и одной из древнейших форм хозяйства. Рыбная ловля имеет своим началом эпоху среднего палеолита, где в тяжёлых спартанских условиях позволяли просуществовать примитивные ловушки, остроги или гарпуны. Однако наиболее интенсивные следы использования ресурсов водной среды для потребления появляются с началом голоцена - после отступления ледников. Наряду с рыбаками, воспринимающими ловлю как способ заработка, появились и те, для которых добыча рыб является формой проведения свободного времени, увлечением и своеобразным стилем жизни. Рыбалка для рыболова - это и отдых, и хобби, связанные с приобретением снаряжения, чтением специализированных журналов и общением с другими такими же любителями. Неотъемлемой частью данного общества является их собственный язык, или социолект, которому и будет посвящена настоящая статья. 
Рыболовная лексика как фрагмент национального языка изредка рассматривалась польскими языковедами, в отличие от русского языка, где некоторые её аспекты многократно подвергались анализу в различных исследованиях. Вместе с тем главный центр внимания российских лингвистов сосредоточился на ихтиологической терминологии, профессиональной лексике рыбаков, и только некоторые работы непосредственно посвящены рыболовному социолекту. Понятие социолект следует рассматривать в рамках социолингвистики, раздела языкознания, предметом исследования которого являются отношения между лингвистическими и социальными фактами. Стоит обратить внимание на то, что в современной лингвистике существует несколько дефиниций социолекта. При этом нет единого подхода к их классификации, а типология социолектов не характеризируется упорядоченностью. Социолекты не создают целостных систем коммуникации. Это лишь особенности речи, а словарно-грамматическая основа социолектов, как правило, в незначительной степени отличается от такой же основы национального языка. Прежде в языкознании встречались другие обозначения. Так, И. Байерова использовала два такие термина - jezzk środowiskowy и język specjalny ${ }^{1}$. В свою очередь, С. Урбанчик ввёл такие термины, как terminologia zawodowa и stownictwo środowiskowe, однако его концепция полностью пропускает явление речевого акта, без которого профессиональный словарный запас не мог бы возникнуть. В статье Р. Токарского Uwagi o gwarze wędkarskiej можно прочитать, что анализируемый нами рыболовный социолект следует рассматривать как один из говоров ${ }^{2}$. Перед созданием понятия социолект европейская лингвистика предлагала термин социальные диалекты.

Прежде чем перейти к анализу рыболовного социолекта, представим коммуникативные ситуации, характерные для данной социальной группы, т. е. то, какие условия дают удильщикам возможность пользоваться своим специфическим языком:

\section{1. Непосредственное общение:}

а) Коммуникация перед рыбалкой. Этот тип общения тесно связан с надлежащей подготовкой рыболовного снаряжения, выбора подходящих аттрактантов и приманок, а также составлением определенного плана действий;

б) Коммуникация во время рыбалки. Разговор в этих условиях ориентирован на передачу короткой и точной информации - доминируют

1 BAJEROWA, I.: Badania nad terminologia języków specjalnych ('środowiskowych). In: Język polski i językoznawstwo polskie w sześćdziesięcioleciu niepodległości. Wrocław-Warszawa-Kraków 1982, s. $37-40$.

2 TOKARSKI, R.: Uwagi o gwarze wędkarskiej. Poradnik językowy, z. 3, s. 111-121. 
команды и экспрессивные призывы, а также тенденция к экономии речевых средств;

в) Коммуникация во время подсечки. В данной ситуации преобладают всякого рода комментарии, команды и замечания, касающиеся рыбы или метода ловли;

г) Коммуникация после рыбалки. В пределах данного разговора имеем дело с отчётом на тему конкретной рыбалки, обменом мнениями, комментариями, передачей личных впечатлений;

д) Коммуникация в рыболовных магазинах. Данная речевая ситуация ориентирована на получение профессиональных знаний или возможности задать вопрос, связанный с техническим аспектом снаряжения;

е) Коммуникация в рыболовных объединениях. В данном случае рыболову предоставляется возможность не только получить необходимые знания у специалистов, но и познать рыбалку с практической точки зрения (напр., через демонстрацию снаряжения).

\section{2. Массовая коммуникация:}

a) Чтение и совместное создание рыболовных форумов, блогов и сайтов. Высказывания в Интернете, в основном, достигают тех же целей, что и непосредственное общение. Глобальная сеть - это место, где рыболов может рассказать о своём опыте, похвалиться своей добычей, поделиться своими взглядами, узнать что-то новое и от других;

б) Чтение прессы и специализированных журналов и книг. Данная ситуация способствует освоению профессиональной части социолекта являясь также источником научно-технической терминологии.

Рыболовный социолект следует рассматривать с нескольких точек зрения. Прежде всего, он представляет собой научно-техническую терминологию, которая является своеобразной почвой для дальнейших преобразований в данном социолекте. С другой стороны, это разговорный вариант национального языка, в пределах которого происходит общение. Рыболовный социолект проявляет большинство характерных языковых тенденций, которые можно наблюдать и в повседневном языке. Не стоит также забывать о значительном воздействии региональных и диалектных форм (напр., из районов Вармийско-Мазурского края или Прикамья). Доступный языковой репертуар считается недостаточным для удовлетворения коммуникативных потребностей данной социальной группы. Если в рыболовном социолекте не хватает необходимого определения, он пополняется за счёт заимствований, неологизмов и неосемантизмов. Важно подчеркнуть, что заимствования могут происходить как из иностранных языков, так и из региональных разновидностей собственного языка. 
Более или менее основательно рассмотреть выявляемый состав единиц задача весьма трудоёмкая, что обусловлено не в последнюю очередь тем, что территориальная дифференциация существенно повлияла на формирование социолектов, обнаруживающих как отличия, так и несомненные сходства. В то же время анализ имеющихся польских и российских источников сделал возможным создание общей классификации:

1. Определения рыболовов.

2. Определения, связанные с рыбалкой:
a) рыболовные техники и методы
б) действия производимые рыболовами
в) поведение рыб

\section{3. Наименования рыболовного снаряжения:}
a) одежда
б) удочка и её составные части
в) сигнализаторы поклёвки
г) катушка и её составные части
д) леска и соединительные элементы
е) крючок и его составные части
ё) грузило
ж) аксессуары

4. Определения видов приманки:
a) блесна и её составные части
б) воблер
в) мушки и мормышки
г) натуральные приманки

5. Определения рыб:
a) названия рыб в зависимости от их величины
б) названия рыб по их видовой принадлежности
в) определения щуки

\section{6. Рыболовные пословицы и поговорки:}

Из вышеуказанной квалификации мы решили выбрать некоторые тематические блоки, в рамках которых образованы слова, определяющие применяемые во время рыбалки орудия лова. Их анализ, с одной стороны, позволяет выявить наиболее выразительные черты рыболовной лексики, а с другой, данная лексика достаточно редко рассматривалась в других научных работах. Мы сосредоточимся на мотивационном и словообразовательном аспектах выбранных нами лексических единиц. 


\section{Блесна и её составные части}

Блесна - это искусственная приманка (насадка) для ловли хищных рыб спиннингом, на дорожку или отвесным блеснением. Представляет собой большую металлическую пластинку овальной формы или удлинённую, оснащенную одинарным, двойным или тройным крючком, и имеющую отверстие для крепления к металлическому поводку или к леске ${ }^{3}$. Глаголы блестеть, btyszczeć послужили словообразовательной основой для создания польского и русского наименований. Необходимо вспомнить, что современные рыболовы выделяют три виды блёсен, первой из которых является колебалка/wahadtówka, подразумевающая под собой металлическую пластинку с отверстиями, в которых находятся заводные кольца (основа колеба- + суффиисы -л-к- + окончание - $a$; основа wahadt + -ówk(a)). Следующим типом блесны является так называемая вращалка/obrotówka, которая характеризируется быстрыми вращательными движениями (основа враща- + суффиксы -л-к- + окончание - $a$; основа obrot + суффикс -ówk(a), чередование ó : o). В свою очередь, блесну, состоящую только из тела и крючка, принято называть балансир/podlodó $\boldsymbol{k} k \boldsymbol{a}$, а её движение зависит от действий, совершаемых рыболовом. Русское определение представляет собой метафоризацию, в то время, как польская лексема образована префиксально-суффиксальным способом (префикс pod- + основа -lod- + суфффикс -ówk(a) чередование ó:o).

Значительная часть определений данного тематического блока образована посредством лексико-семантического способа, подразумевающего метонимический перенос, к примеру: железка/żelastwo (блесна, сделанная из железа), ложка/tyżka (блесна из ложки), медь (блесна из меди) или олово/cynówka (блесна, изготовленная из олова). Как можно заметить, большинство из приведенных названий имеет переводной эквивалент в другом языке. Метонимия также прослеживается в некоторых наименованиях блёсен, получивших своё название от местностей, в которых были изготовлены: trzebiatówki, karlinki (совершают характерные покачивания из стороны в сторону; от городов Trzebiatów и Karlin), волга (удлинённая и широкая колеблющаяся блесна с насечками глаз и чешуи рыбы на выпуклой стороне; от реки Волга), женева (блесна из латуни или меди, предназначена для ловли щуки и окуня; от города Женева) или канада (блесна ложкообразной формы; от названия страны Канада). В отдельных случаях наименование компании, специализирующейся в производстве колеблющихся пластинок, может послужить мотивационной основой создания определений, таких как alga (блесна для ловли щуки).

3 MATVEJEV, M. M.: Sputnik rybolova-sportsmena. Moskva: Sovetskaja Rossija, 196o, s. 124. 
Такие названия сильно распространены как в Польше, так и в России (другие примеры - comet, gnom, meps, pirat).

Анализируемый нами лексический состав содержит также определения, возникшие посредством метафорического переноса названий с одной реалии на другую по причине сходства их внешнего вида. Если посмотреть на боковую сторону блесны о названии $\boldsymbol{e s} \boldsymbol{k} \boldsymbol{a}$, то, несомненно, будет она ассоциироваться с латинской буквой «S». B ящике опытного любителя зимней рыбалки обязательно должны быть блесны, такие как драконы или крабы/kraby, характеризующиеся большим количеством огромных крючков, благодаря которым намного легче удачно подцепить рыбу. По внешнему виду они напоминают указанные живые существа, однако данная снасть считается браконьерской, из-за частых и тяжёлых увечий рыбы во время клёва.

Достаточно активным мотивационным признаком в данной категории является вид определённой рыбы, что видно в лексемах, типа голавалица (блесна из латуни, выпуклая сторона которой ярко начищается; суффикс -иц-), окунёвка (блесна из серебряной пластинки, имеющая ложкообразную форму; суфффикс -овк-) или toby (металлическая пластинка, имитирующая балтийскую песчанку; социолектное определение возникло от сокращения польского наименования этой рыбы, т. е. tobiasz). В данном месте необходимо подчеркнуть, что эти блесны не только напоминают конкретное морское животное, но и указывают своим внешним видом, для ловли какой рыбы предназначена данная снасть.

В русском социолекте мы зафиксировали также слова, учитывающие звуковые особенности приманки. Акустические блесны подразумевают под собой специфические пластинки, которые во время своего движения издают различные шумы, отвечающие за привлечение внимания рыбы. Как легко можно догадаться, их определения возникли от соответствующих звукоподражательных глаголов, и они образованы суффиксальным способом по продуктивной словообразовательной модели «основа глагола + суффикс -лк-»: звенелка (от глагола звенеть), шумелка (от глагола шуметь). В свою очередь, в основу мотивации лексемы дурилка (от глагола дурить) легла функция приманки, которая представляется следующим образом: блесна подразумевает предмет, при помощи которого дурят рыбу ${ }^{4}$. Однако этого предмета не следует смешивать с длинной бечёвкой с привязанным к ней на проволоке крючком, о том же наименовании.

4 CHALJUKOV, Ju. V.: Leksika orlovskich rybakov. Orel 2008, s. 139. 


\section{Сигнализаторы поклёвки}

Среди зафиксированных нами наименований сигнализаторов поклёвки можно выделить определения поплавка/splawika и их составные части, акустических сигнализаторов и индикаторов поклёвки, а подавляющее большинство из них имеет свои соответствия в обоих языках. Название главного объекта нашего анализа обладает следующей этимологией: слово поплавок происходит от глагола плавать, а польский эквивалент возник от существительного sptaw 'перевозка морским путём, при использовании потока воды'.

Немалое количество наименований поплавка образовано лексико-семантическим способом вследствие метафоризации. Небольшой сигнализатор, отличающийся длинной и узкой формой, называется словами карандаш/ /ołówek, стрелa/strzata или papieros. В свою очередь, крупный и пузатый поплавок круглой формы, предназначенный для ловли хищных рыб, определяется словом бомба/bomba. Сплющенный поплавок треугольной формы получил в польском социолекте название żagiel. Иногда мотивационным основанием для создания наименований могут быть блюда отечественной кухни. Некоторым русским рыболовам сплюснутая форма поплавка, который при подъёме всплывает и ложится на бок, ассоциируется с блином, что в рамках социолекта привело к метафорическому переносу названий с одного предмета на другой. Интересным с точки зрения языкового анализа является поплавок обезьянка/matpka, принцип работы которого послужил мотивационным аспектом для его названия. Он состоит из пластмассовой части, которая движется по металлическому стержню, вертикально забитому под удочкой. Когда рыболову удастся зацепить рыбу, упомянутый пластмассовый индикатор поднимается вверх по стержню, напоминая движения обезьяны, которая поднимается по пальме (англ. monkey climber). Арбалет - это один из разновидностей кивка (окончание вершинки в подледной удочке), название которого происходит по основанию сходства с боевым метательным оружием о том же наименований. Он применяется в зимнее время для ловли рыбы с донным типом питания, а в Польше такая снасть практически не используется, из-за низкой популярности зимней рыбалки.

Как мы уже отметили, метонимия является одной из наиболее выразительных черт рыболовной лексики, а некоторые наименования поплавка только свидетельствуют об активном употреблении данного способа словообразования. Материалом для изготовления сигнализатора поклёвки могут послужить сырьё, такое как дерево бальзы/balsy, перо/pióro птицы, игла/kolec дикобраза или пенопласт/styropian. В свою очередь, Авон/Avon подразумевает под собой 
длинный, полный поплавок о хорошей стабильности, отличающийся короткой антенной. Получил своё название от реки, расположенной на юго-западе Англии, с тем же названием.

Анализируемый нами лексический состав - это не исключение, если говорить о присутствии многочисленных англицизмов. Поплавок стик/stick представляет собой длинное и тонкое устройство и напоминает ручку или карандаш. Само слово stick обозначает палочку и в такой форме часто встречается в русском социолекте. В свою очередь, дарт/dart - это поплавок, который обеспечивает точный заброс приманки, а его наименование происходит от английского слова dart, обозначающего стрелку. В рыболовном снаряжении встречаются также поплавки, дополнительно обладающие специальными кольцами, которые делают возможным свободное перемещение лески. Примером такого сигнализатора является ваглер/waggler, применяемый удильщиками при ловле на дальний заброс, а своё название получил от английского слова wag 'вилять, махать хвостом'. Поплавок в форме металлической ручки, которого устанавливают на электронном сигнализаторе, принято называть словом свингеp/swinger (от слова swing 'качание, колебание' (+ -er/-ер)). Данная снасть сильно распространена в русском и польском рыболовном обществе, потому что обеспечивает точное натяжение лески, а также визуально «информирует» рыболова о клёве рыбы.

Если говорить об электронных индикаторах поклёвки, обязательно надо вспомнить о датчике (польс. czujnik), отличающийся небольшим размером, и размещается его на бланке удилища. Основой для русского определения послужил глагол $\partial a m b$, что в данном случае может обозначать 'дать сигнал' (да+ -m-чuк), так как движения рыбы, попавшей на крючок, приводят к появлению соответствующей информации на экране. В свою очередь, польское название содержит в себе суффикс -nik. Примером словосочетания в данной категории является выражение водной шар / kula wodna, определяющее поплавок в виде пустого шара с отверстиями. Когда рыба оказывается на крючке, он начинает погружаться в воду.

\section{Рыболовные аксессуары}

В эту группу мы зачислили все типы рыболовного снаряжения, которые представляют собой самостоятельные аксессуары, а не элементы, прикреплённые к удочке. Одним из самых важных рыболовных инструментов является сетчатый мешок на рукоятке для извлечения рыбы из воды, отсутствие которого часто грозит штрафом. Речь идёт о так называемом подсачке/podbie$\boldsymbol{r a k u}$, словообразовательная структура которого представляется следующим 
образом: под- + сачок (префиксальный способ словообразования); основа глагола podbierać + суфффикс -ak (суфффиксация). Благодаря германизированным районам Варминьско-Мазурского края, в польский рыболовный социолект попали также такие наименования, как kasar, kasarek, kaszor ${ }^{5}$ (от нем. Der Käscher), podchwytka (от глагола podchwyt(yw)ać, суффикс -ka), однако большинство из этих определений используют только пожилые рыболовы.

Практика любительского рыболовства, заключающаяся в освобождении пойманной рыбы, чтобы таким образом не причинить ей вреда, определяется английским термином nokill. Этому принципу можно следовать посредством применения таких аксессуаров, как зевник/rozwieracz или экстрактор/wypychacz. Первый инструмент позволяет широко раскрыть пасть рыбы и удержать её в таком состоянии, чтобы извлечь приманку (корень зев- + суффикс -ник; основа глагола rozwierać +суфффикс -acz). В свою очередь, экстрактор/wypychacz - длинное и тонкое приспособление для извлечения крючка из пасти хищной рыбы (русское слово заимствовано, а польское образовано от глагола $w y p y c h a c ́$ + -acz;). Пригодный аксессуар для освобождения крючков и блёсен от зацепов рыболовы определяют словом отцеп/odczepiacz. Русское наименование образовано бессуфискальным способом словообразования (от глагола отцепить), в то время, как польская лексема представляет собой следующий пример суффиксации (основа глагола odczepiać + -acz). Англицизмом в данном тематическом блоке является субстантив липгрип/lipgrip, который позволяет захватить и удержать пойманную рыбу за челюсть, во избежание травм, а потом сфотографироваться с добычей. Для этой снасти употребляются как синонимы слова захват/chwytak.

Как русский, так и польский социолекты содержат наименования для других, довольно распространённых оборудований, которые применяются для измерения глубины водохранилища. Мы имеем в виду так называемые глубиномеры/gruntomierze (сложения: глубин-о-мер/grunt-o-mierz), одна из разновидностей которых представляет собой привязанное к верёвке грузило и именуется лексемой stukadetko (основа звукоподражательного глагола stukać + суффикс -detko). В свою очередь, лексема telewizor образована лексико-семантическим способом вследствие метафорического переноса: telewizor 'электронное устройство для отображения телевизионных программ' $\rightarrow$ telewizor 'навигационный прибор, показывающий на экране глубину водоёма'. Некоторые рыболовы охотно используют устройство для аэрации ящиков, которые делают возможным удержать рыбу в живом состоянии. Данный

5 ZAMOŚCIŃSKI, K.: Narzędzia i sprzęty rybackie oraz metody połowu w kaszubskim rybotówstwie jeziornym. In: Jem jô rëbôk... Rybołówstwo na Kaszubach - tradycja i współczesność. Wieżyca 2014, s. 177 . 
инструмент принято называть аэратором/napowietrzaczem (польское слово представляет собой пример суффиксального способа: napowietrzacz $\rightarrow$ основа глагола napowietrzać + суффикс -acz; русское аэратор - заимствование). Гораздо более сложным устройством является флэшер/flasher (англ. flasher 'мигалка'), который с помощью ультразвуковых сигналов способен контролировать то, что происходит под поверхностью льда. В отличие от эхолота, он применяется преимущественно для подлёдной рыбалки.

Русский рыболовный социолект очень богат различными лексемами, определяющими инструменты для зимней ловли, что обусловлено культурно-историческими и географическими факторами. Опытный рыболов-зимник никогда не забудет взять с собой шарабана, который подразумевает под собой самостоятельно изготовленный ящик для хранения необходимых предметов, облегчающих рыбалку. Данное слово происходит от французского словосочетания char à bancs, называвшего 'семейные дрожки, открытый фаэтон с несколькими рядами сидений'. В свою очередь, этимология слова шумовка берёт своё начало из польского языка, от глагола szumować, т.е. снимать пену. Данный инструмент представляет собой черпак для удаления из лунки кусочков льда, а рукоятку обычно изготовляют из теплых материалов. Примером браконьерского приспособления является квок - это колотушка, которая производит булькающие звуки при ударе о воду (откуда возникло название данного инструмента). Этот аксессуар применяется преимущественно при ловле сома, и поэтому принято его синонимично определять названием сомовка (сом-ов-к-a). В настоящее время использование сетей в процессе рыбалки является запрещённым, но в некоторых районах России легально применяется малявочница/podrywka. Она представляет собой конструкцию из сетки с отверстиями, в которые попадают небольшие рыбы (живцы). Русская лексема получила название от слова малявка (маленькая рыбка) и образована посредством присоединения суффикса -ниц-. Польская лексема образовалось от глагола podrywać в значении 'быстро что-то/кого-то поднимать' при помощи суффикса $-k(a)$.

Проделанный конфронтативный анализ наименований орудий лова подтверждает представления о том, что рыболовная лексика может стать интересным материалом, требующим пристального внимания лингвистов. Процессы глобализации, международные рыболовные соревнования привели к тому, что в настоящее время наблюдается больше сходств, чем различий в употреблении данного типа лексики. Не подлежит сомнению факт, что рыболовы используют весь перечень возможностей, касающихся мотивации для образования новых слов. Как русский, так и польский рыболовный социолекты для создания новых слов чаще всего используют суфффиксальный 
и лексико-семантический способ словообразования. В предлагаемой статьи мы ограничились определённым количеством языковых единиц рыболовного социолекта, однако весьма перспективной видится возможность продолжать исследования в области лексики русских и польских рыболовов. На наш взгляд, необходим более тщательный анализ наименований орудия лова, которые представляют собой группу номинативных единиц с точки зрения их этимологии и словообразовательной структуры.

\section{Литература:}

BAJEROWA, I.: Badania nad terminologia języków specjalnych (środowiskowych). In: Język polski i językoznawstwo polskie w sześćdziesięcioleciu niepodległości. Wrocław-Warszawa-Kraków 1982, s. 37-40.

CHALJUKOV, Ju. V.: Leksika orlovskich rybakov. Orel 2008.

MATVEJEV, M. M.: Sputnik rybolova-sportsmena. Moskva: Sovetskaja Rossija, 1960.

TOKARSKI, R.: Uwagi o gwarze wędkarskiej. Poradnik językowy, z. 3, s. 111-121.

ZAMOŚCIŃSKI, K.: Narzędzia i sprzęty rybackie oraz metody polowu w kaszubskim rybołówstwie jeziornym. In: Jem jô rëbôk... Rybołówstwo na Kaszubach - tradycja i współczesność. Wieżyca 2014, s. 111-256.

\section{About the author}

Aleksandra Zięba

University of Silesia, Faculty of Humanities, Department of Russian Studies, Katowice, Poland

aleksandrazieba33@gmail.com

https://orcid.org/0000-0001-6897-5777

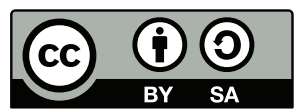

This work can be used in accordance with the Creative Commons BY-SA 4.0 International license terms and conditions (<https://creativecommons.org/licenses/by-sa/4.0/legalcode>). This does not apply to works or elements (such as images or photographs) that are used in the work under a contractual license or exception or limitation to relevant rights. 